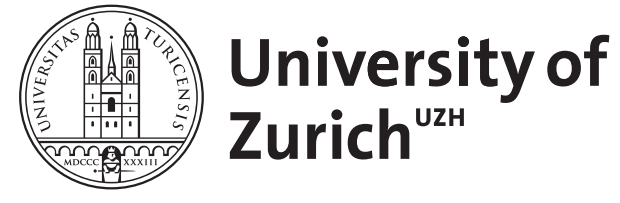
Archive

University of Zurich

University Library

Strickhofstrasse 39

CH-8057 Zurich

www.zora.uzh.ch

Year: 2021

Don't make a fetish of faults : a vindication of moral luck

Riedener, Stefan

DOI: https://doi.org/10.1007/s11098-020-01452-9

Posted at the Zurich Open Repository and Archive, University of Zurich

ZORA URL: https://doi.org/10.5167/uzh-187292

Journal Article

Published Version

Originally published at:

Riedener, Stefan (2021). Don't make a fetish of faults : a vindication of moral luck. Philosophical Studies, 178(3):693-711.

DOI: https://doi.org/10.1007/s11098-020-01452-9 


\title{
Don't make a fetish of faults: a vindication of moral luck
}

\author{
Stefan Riedener ${ }^{1}$
}

(C) Springer Nature B.V. 2020

\begin{abstract}
Is it appropriate to blame people unequally if the only difference between them was a matter of luck? Suppose Alice would drive recklessly if she could, Belen drove recklessly but didn't harm anyone, and Cleo drove recklessly and killed a child. Luck-advocates emphasize that in real life we do blame such agents very unequally. Luck-skeptics counter that people aren't responsible for factors beyond their control, or beyond their quality of will. I'll defend a somewhat reconciliatory view. I'll concede to the skeptics that these agents are equally culpable. Nonetheless, I'll suggest with the luck-advocates that it's fitting to blame them unequally. That's because their culpability is unequally significant for us: Cleo's culpability concerns us more than Belen's, and Belen's more than Alice's-just like the fault of a close aggressor concerns us more than that of an aggressor far off in place and time. And it's fitting for us to respond with more blame to faults that concern us more. Indeed, blaming people simply in proportion to their culpability manifests a form of fetishism, or problematic mere-matter-of-principle concern. So while many skeptical tenets may hold, in substance the luck-advocates are right.
\end{abstract}

Keywords Moral luck · Reactive attitudes · Blame $\cdot$ Agent-relativity $\cdot$ Fittingness of emotions

\section{Introduction}

Is it appropriate to blame people unequally if the only difference between them was a matter of luck? Consider a classic range of cases (from Nagel 1979). Alice is disposed to drive recklessly, and would do so in Zara's neighborhood if

Stefan Riedener

stefan.riedener@philos.uzh.ch

1 Department of Philosophy, University of Zurich, Zollikerstrasse 117, 8008 Zurich, Switzerland 
circumstances allowed. But she's prevented from getting a license, and never approaches Zara's daughter Yael. Belen has that same disposition, and a license to boot, and drives recklessly past Zara's house one day. But as Yael is playing in the garden, they all emerge unscathed. Cleo shares that disposition as well. And when she drives recklessly on Zara's street, Yael is playing on the sidewalk, and killed in the ensuing collision. The degree of recklessness, which Alice would have evinced, with which Belen threatened and Cleo killed Yael, is the same. It's objectionable. And our agents are all responsible adults. So the only difference between them is their bad luck in being permitted by circumstances to drive, or in this driving resulting in a collision.

Now on the one hand, in Zara's place, most of us would be furious at Cleo perhaps until the end of our lives, hold a much milder grudge against Belen for a much shorter time, and respond with little if any indignation to Alice. And this seems appropriate. After all, nothing happened in Alice's case, whereas Cleo killed Zara's child-or so the luck-advocates typically emphasize (see e.g. Moore 2009; Hanna 2014; Hartman 2017; Kumar 2018; or relatedly Walker 1991 or Nagel 1979). On the other hand, it seems inappropriate for Zara to blame our agents unequally. After all, the difference between them was a matter beyond their control, and beyond their quality of will, and it seems unfair to hold them responsible for such matters. Thus our common practice seems at best to express some inappropriate biases-or so the luck-skeptics typically claim (see e.g. Smith 2002, II.iii; Nagel 1979; Williams 1995; Zimmerman 1987; Harman 1999; Domsky 2004; Enoch and Marmor 2007; Levy 2011 or Wolf 2013, among many others).

In this paper, I'll defend a view that's somewhat reconciliatory. I'll concede many of the skeptics' main tenets. The faults of our agents are intrinsically equal. So they are equally culpable. And perhaps it is unfair if they face unequal responses. Nonetheless, I'll suggest with the luck-advocates that it's fitting for Zara to blame them unequally. That's because their culpability is unequally significant for her: Cleo's culpability concerns Zara more than Belen's, and Belen's more than Alice's - just like the fault of a close aggressor concerns her more than that of an aggressor distant in time and place. And it's fitting for Zara to respond with more blame to faults that concern her more. Indeed, and this will be the key conclusion of my paper, blaming people simply in proportion to their culpability-as perhaps fairness alone would commend-manifests a form of fetishism, or problematic mere-matter-of-principle concern. So while many skeptical tenets may hold, in substance the luck-advocates are right.

The rough idea that our agents' faults are unequally significant for Zara was suggested by Scanlon (2008). I'll develop the idea very differently from him. But a brief discussion of Scanlon will illuminate some desiderata for how to turn his rough idea into a pertinent vindication of luck. So I'll start with that (Sect. 2). In the remainder of the paper, I'll then argue that our central blame-responses are sensitive to significance (Sect. 3), provide an account of when a fact is significant for you (Sect. 4), and substantiate that our agents' faults are unequally significant for Zara (Sect. 5). And I'll argue that this grounds an important vindication of moral luck- 
to the effect that luck-insensitivity would make a fetish of our agents' faults (Sect. 6). ${ }^{1}$

\section{Scanlon and three desiderata}

So let's start with a discussion of Scanlon. In his Moral Dimensions, Scanlon champions a specific account of blame. On this account, you blame me for an action if you judge that it shows something about my attitudes toward others that impairs the relationships they can appropriately have with me, and modify your relationship to me in accordance with this judgment (2008, p. 128f.). For Scanlon, a relationship is a complex set of attitudes, expectations and dispositions. So reactive emotions like resentment or indignation may, but needn't be part of such blame. You might blame me for an action by no longer trusting me or enjoying my company unreservedly due to the attitudes I've manifested, say, even if you don't feel any resentment or indignation at me (e.g. 2008, p. 173). Let's call this revision of relationships 'Scanlon-blame'.

One argument Scanlon gives for this account hinges on moral luck. He assumes that moral luck is a fact: that it's appropriate for Zara to blame our agents unequally. And he suggests that his account of blame best captures this fact. More specifically, Scanlon argues that the extent to which it's appropriate for you to revise your relationship to me depends not just on the quality of my attitudes, but also on the 'significance' that these attitudes have for you (2008, p. 150). Scanlon says very little about what he means by this. But he illustrates it with our classic examples (referring to agents like Alice, Belen and Cleo as $B, C$ and $D$ respectively):

B's relations with others are impaired by his lack of regard for their safety. He is open to criticism on this account. But (assuming that his recklessness does not affect other aspects of his relations with others) the fact that he would drive recklessly if he drove gives people little reason to revise their attitudes toward him. It affects his relations with them very little if at all. C, by contrast, actually endangers people. So her defects of character have a significance for them that B's do not. It therefore makes sense for them [...] to stay out of her way and not loan her their cars, [and] to regard her not as a "fun person" whose foibles should be shrugged off, but as person whose priorities are a threat to them [...]. D's faults have greater significance than C's for those who are affected by his driving: he is not only the person who killed a child but also the person whose recklessness led to the child's death. The fact that his fault

\footnotetext{
1 Note that my question concerns only so-called circumstantial and resultant luck. There are other forms of luck-such as constitutive and causal luck (see e.g. Nagel 1979). Personally, I think these forms of luck don't undermine our practice of responsibility either. And that's compatible with what I'll say. But I won't discuss this here. Also, my question will only be whether luck may affect the strength of the appropriate responses to us. There's also a question about whether it can affect the kind of response that's appropriate - affect whether our actions warrant praise or blame (see e.g. Williams 1981b). As far as the rationale of this paper goes, it doesn't. But again I won't discuss this here.
} 
has played this significant role in their lives raises a greater question about how they are going to understand their relations with him. (2008, p. 149)

In short, it's appropriate for Zara to distance herself more from Belen than from Alice since only Belen actually poses a threat, and from Cleo than from Belen since only Cleo's recklessness was actually life-changing. More generally, Scanlon-blame isn't a mere assessment of the moral quality of someone's attitudes. It's also $\left(\right.$ appropriately $\left.^{2}\right)$ sensitive to the significance of their fault for us. And our agents' faults are unequally significant for Zara. Scanlon suggests that the same doesn't hold for traditional understandings of blame - and in particular, not for Strawsonian reactive emotions. According to Strawson, the reactive attitudes are 'essentially reactions to the quality of others' wills' (2008, p. 15), and thus apparently not to the actions they (un)luckily end up performing or the effects that these actions (un)luckily have, or to a form of significance grounded on such factors. So Scanlon concludes that Strawson's account 'fails to explain the plausibility of moral outcome luck' (2008, p. 128), or that moral luck provides an argument for his conception of blame.

I think Scanlon's rough idea is right. Blame isn't a mere assessment of someone's attitudes, but also sensitive to the import of these attitudes for you. And this grounds a form of moral luck. In fact, I think it does so in a manner that should trouble luckskeptics. Yet Scanlon's own elaboration of this idea arguably needn't trouble them much. First of all, Scanlon doesn't argue for his claim that blame is sensitive to significance in a sense in which our agents' faults are unequally significant for Zara. He basically just states that that's so. ${ }^{3}$ Or as mentioned, his only argument is that this explains why Zara may blame our agents unequally. But many luck-skeptics simply doubt that she may. They'll suggest that Cleo's killing warrants extra sadness, or that Belen's threat warrants extra concern-but not that they justify any more blame than is appropriate in response to Alice. So unless we have an independent positive argument for this, they'll doubt that blame is sensitive to significance and thus sensitive to luck. We need an independent rationale for this claim, lest we beg the question against these skeptics.

Now perhaps Scanlon didn't give any argument for why Zara may blame our agents unequally because when restricted to Scanlon-blame, this seems eminently plausible. But that's just because so understood the claim is extremely weak. Note that as long as you're untrustworthy or somewhat unenjoyable company, it's appropriate to Scanlon-blame you-to refuse to trust you or consider you a candidate friend. And that's so even if you're the victim of a terrible childhood, or a diagnosed psychopath, say (2008, p. 149). So to Scanlon-blame you is to 'hold you responsible' in a very weak sense. In fact, no responsibility-skeptic ever denied the appropriateness of such blame (see explicitly e.g. Pereboom 2014, Chap. 6). By the

\footnotetext{
${ }^{2}$ By the locution that some response $R$ 'is sensitive to' some factor $F$, I don't mean that it depends on $F$ whether we actually have $R$. I always mean it depends on $F$ whether some form of $R$ is appropriate or fitting. I'll henceforth omit the qualifier.

${ }^{3}$ Cholbi (2014, p. 322) criticizes this too: 'Scanlon offers no reasons why such significance of lucky outcomes should influence the impairment of our relationships'.
} 
same token, few luck-skeptics would deny that Scanlon-blame is sensitive to luck. Of course Zara may be more guarded vis-à-vis Belen than vis-à-vis Alice: she might just appreciate that Belen's dangerous whereas Alice is not. And of course she may be more reluctant to consider Cleo a candidate friend than Belen: she might simply find the constant reminding of Cleo's fatal recklessness hard to bear. In doing so she needn't ascribe to our agents any controversial responsibility for something beyond their control. So Scanlon may have shown that there's one, relatively undemanding practice of 'holding people responsible', which is sensitive to luck. But for all he's shown, we might have a more demanding practice of doing so that isn' $t$ so sensitive. And that's just what most skeptics claimed. Indeed, Scanlon's overall argument seems to corroborate their skepticism. Prima facie, our most demanding practice of holding people responsible are the reactive attitudes. So it's the appropriateness of these attitudes, or their sensitivity to luck, that responsibility- or luck-skeptics have generally doubted (see e.g. Pereboom 2001, p. 200; Levy 2011, p. 8; also Browne 1992 or Williams 1995). And Scanlon's own argument suggests that these attitudes aren't sensitive to luck. So his specific argument needn't trouble these skeptics. To address these skeptics' doubts, we must show (contra Scanlon himself) that even the reactive attitudes are sensitive to significance-or indeed that any sensible responsibility-practice is.

There's a related third worry one might raise. Suppose that Zara just appreciates that Belen's recklessness is more dangerous than Alice's, and finds the reminding of Cleo's heedlessness harder to bear than similar reminding of Belen's. Then it's arguably for prudential considerations that their faults matter unequally to her. In other words, it seems that Scanlon-blame is a complex response, sensitive to both moral and non-moral concerns, and that this makes it sensitive to luck. But if that's so, there's another respect in which Scanlon's argument misses typical skeptical doubts, even if it applies to reactive emotions or any other overall sensible practice. Suppose the reactive attitudes too were somehow sensitive to both moral and nonmoral considerations, that our agents' faults raised unequal non-moral concerns, and that it was only therefore appropriate for Zara to respond with unequal attitudes. Then such attitudes would at best amount to a morally suboptimal but all-thingsconsidered appropriate response. A person exclusively sensitive to the moral considerations would still blame our agents equally. But presumably many skeptics wanted to say just that. They didn't doubt that non-moral considerations may somehow warrant unequal responses to our cases. They doubted that it can be fair, or more generally appropriate as far as moral considerations go, to blame our agents unequally (see e.g. Williams 1995). So to address these skeptics' doubts, we need to show that significance is a distinctly moral factor, or that equal blame would manifest an insensitivity to the moral considerations at issue, and thus be a morally problematic response. ${ }^{4}$

There are other worries one might have about Scanlon's approach (see e.g. Cholbi 2014; Stout 2017). Most fundamentally, one might question whether any

\footnotetext{
4 The fact that Scanlon-blame seems partially a response to prudential considerations may be a more general problem for Scanlon. I suggest this in Riedener (2019).
} 
claim about the appropriateness of certain responses can be pertinent to skeptical doubts. One might suggest skeptics never doubted that our cases render fitting unequal blame-responses. They only doubted that our agents are unequally culpable, or deserve unequal blame in some much more basic sense-in a sense that's independent of fitting-attitude facts, and that Scanlon's argument doesn't affect in the first place. This will be a worry that my account also invites. I'll introduce it properly, and address it, in Sect. 6. So let's leave it at that for now. If we're to exploit Scanlon's idea for the moral luck debate, we must anyway develop it very differently. We need an independent argument to the effect that blame is appropriately sensitive to significance. We must show that that's so even for resentment and indignation, or indeed for any sensible practice of holding people responsible. And we must establish that equal blame would constitute a morally problematic response. Let's turn to this now.

\section{The significance of value-facts}

In the remainder of this paper, I'll focus primarily on the reactive attitudes. I'll presuppose that these attitudes have internal correctness or 'fittingness' conditions, and my question will be about these (see classically D'Arms and Jacobson 2000, or more recently e.g. Sharadin 2016). I'll say that they're a fitting response, at least among else, to the fact that someone is 'culpable'. And I'll assume that someone's culpability is fully determined by their quality of will-where that's a function of mere dispositions or character, so that our agents have the same quality of will (see e.g. Thomson 1989, pp. 214-215; Rescher 1990, pp. 12-13, or Peels 2015, p. 80). My question in what follows will be whether the strength of the attitude it's fitting for me to have to you is just a function of your culpability or will-or also a function of the significance your culpability has for me. I think the latter claim is very plausible, and independently of moral luck. So I'll set moral luck aside for now, and come back to it only in Sect. 5. Instead, let's start with some general observations about our emotional lives.

Note that as a matter of fact, and quite apart from moral luck, no one's reactive attitudes are just sensitive to people's wills. Suppose Dahir hit someone with wrongful aggression in fifth century Mali. And suppose Zara's friend Emma hit a stranger, and Zara's husband was hit by a stranger called Finn, with that same aggression. Suppose they all manifested an equally objectionable will, and Zara knows this. Then in some sense, intrinsically, they warrant the same degree of indignation. Yet it would be natural for Zara to care more about Emma and Finn's culpability than about Dahir's. That is (as I'll use the term 'caring'), it would be natural for her to be more affected by the indignation that the close culpability intrinsically warrants than by the equal indignation that the far-off culpability does. So it would ultimately be natural for her to feel more indignation in response to Emma and Finn than to Dahir. The same is true for very many emotions, or many kinds of value-facts. The nocturnal earthquake, which destroyed a vase at Zara's home near Bogotá, may have been objectively equally bad as some earthquake in third century China. Still, it would be natural for Zara to react with deeper sadness 
to it. The latest Annapurna ascent may have been equally admirable as some recent record in breath-hold diving. But if Zara is a passionate mountaineer, who has nothing to do with diving, it would be natural for her to react with more admiration to the former. Zara will feel greater relief when someone escapes death in front of her eyes, more grief when the extinct species was one she'd often seen in her garden, and more ardent hope when blessings could befall her beloved.

So as a psychological fact, the ultimate strength of our attitudes seems a function of two factors: the degree of the value-property we take something to intrinsically have; and the extent to which we care about it, or the significance we take it to have for us. ${ }^{5}$ But is this normatively appropriate, or fitting? There are two extreme views we could take on this. First, we might suggest our emotions are only fitting if we take all value-facts to be equally significant for us, or care equally about them. So Zara must respond equally to the China and Colombia earthquakes, say, or her sadness won't fit the facts. Proponents of agent-neutral moral theories, such as classical utilitarians, may find this view congenial. ${ }^{6}$ But intuitively it's quite implausible. We do stand in very unequal relationships to value-facts. And these relationships seem to matter. At the very least, some differentiating forms of caring seem fitting. It's not that all of us constantly have wildly unfitting emotions, given our agent-relative ways of being affected. There's a second extreme view we could take. We might suggest we have complete normative discretion over how significant we take facts to be for us, or how much we care about them. So Zara may care more about the Colombia than the China earthquake or vice versa, her emotions will be fitting either way. Internalists about reasons (see classically Williams 1981a) or thoroughgoing Frankfurtians (see Frankfurt 2004, e.g. p. 22) may find such a view congenial. But intuitively it's implausible too. Sure, we seem to have some normative discretion in what we care about. Zara may always fittingly start to care somewhat less about her longstanding acquaintances and somewhat more about new people, say. But we don't have complete such discretion. If someone's dying in front of her eyes, it would be unfitting for Zara not to care, or to suddenly care more about the demise of some random twelfth century Norwegian than about the death right before her. And it would be unfitting for her not to care, from one moment to the next, about the death of her husband, the failure of her life project, or the awesomeness of what her longstanding rival achieved. Some forms of caring are unfitting. It's not that we may be affected by fact as we please. In short, I take it, our differentiating forms of caring aren't just an irrational bias, nor an arational subjective sensation. They're responses to genuine reasons. The fact that a person was your life-long best friend is a reason to care about their death, but the fact that the person was $5 \mathrm{ft}$. 8 in. tall or had the same number of hairs as you generally isn't. And our carings are fitting if and only if they reflect these reasons.

\footnotetext{
5 Note that as I use the term 'caring', it designates only one dimension of your emotion. On my terminology, you may care more about a close but morally less serious wrong than about a distant but more serious one, even if on the whole you feel more indignation about the latter. Whether this corresponds to our ordinary use of this term I don't know. But it's a helpful explication for our purposes.

${ }^{6}$ Some consequences and variations of this view are explored in Lovett and Riedener (2019).
} 
Let's put this a little more formally. Call a property $F$ that intrinsically, or in itself, renders a certain emotion fitting a 'value-property'. So value-properties include something's being bad, extremely admirable, a ground for some hope, and so on. Call an instantiation of such a property-i.e., a fact $p$ of the form that some $x$ is $F-\mathrm{a}$ 'value-fact'. Value-facts include the fact that this earthquake was bad, that that ascent was very admirable, that these prospects are grounds for some hope, et cetera. Now in saying that a certain value-fact $p$ is (more/less) significant for you, I mean that due to your relationship to $p$ you have reasons-i.e., it would be fitting for you-to be (more/less) affected by the emotions that $x$ 's being $F$ intrinsically warrants. If you are (more/less) so affected, for these reasons, I'll say that you care (more/less) about $p$. For instance, that the China earthquake's badness isn't very significant for Zara means that due to her distant relationship to it, she's got reasons to care little about it, or be only weakly affected by the sadness it intrinsically warrants. It means that since it doesn't concern her much, it's fitting for her to respond with relatively little sadness to it. If I'm right, very many value facts can be (more/less) significant for you in this sense.

So how about the reactive attitudes? If they fit this general picture, then the strength of the attitude it's fitting for me to adopt to you isn't just a function of your will. It's also a function of how significant your will is for me. And intuitively, that's why Zara may fittingly respond with more indignation to Emma and Finn than to Dahir.

\section{An account of significance}

I take it the cases I've presented are intuitive. And perhaps it's also intuitive that Cleo's culpability is more significant for Zara than Belen's, and Belen's more than Alice's. But to establish what kind of mistake Zara'd make in ignoring this unequal significance-in particular, to show she'd make a moral mistake-we need to substantiate this further. We need an account of what makes a value-fact significant for you. ${ }^{7}$ So let me indicate the outlines of an account of significance that I think is plausible. The intuitive idea behind it is that value-facts generally aren't brute. They have grounds: there are reasons for why an earthquake is bad, a climb admirable, or why our agents are culpable. And a value-fact is significant for you to the extent that you're bound up with its grounds.

Here's a way of spelling this out. We can think of the relevant relationship between you and a value-fact $p$ as a relationship between two sets of facts. The first is what I'll call 'the facts that currently constitute your life'. This set comprises all facts that currently hold about you. It might involve facts about your current sense experience, about your memories, the relationships you're in, and so on. The second set of facts is the facts that ground or constitute $p$. If $p$ is the fact that $x$ has some value-property $F$, this set involves the fact that $x$ is $F$, as well as facts about why $x$ is

\footnotetext{
${ }^{7}$ If the picture I've sketched is right, that's a very important general question for the philosophy of emotions. See e.g. Nussbaum (2001), Frankfurt (2004), Helm (2009) and Kolodny (2010) for interesting explorations.
} 
$F$. Now on the proposal I want to advance, $p$ is significant for you to the extent that those facts that ground or constitute $p$ are present in the facts that currently constitute your life. If the facts that ground or constitute $p$ are very present in these facts of your life, then $p$ is significant for you-or you have reasons to be strongly affected by the emotion that $x$ 's being $F$ intrinsically warrants. If those facts aren't present in the facts of your life, then $p$ isn't significant for you-or you have reasons to be only weakly affected by that emotion. ${ }^{8}$

To illustrate this idea, let me elaborate on how it applies to some cases we've considered. Take the fact that the Colombia earthquake was bad. Presumably, this fact is partly grounded in the practical, aesthetic or historical value of the things it destroyed; in the fact that the death of the victims was bad for them or that it would have been good for them to keep enjoying twenty-first century Colombia; in the losses of the bereaved, and so forth. Earthquakes matter because things and people do. Now all of these grounds are quite present in Zara's life. She's experienced the blisses of current Colombia, has perhaps often been confronted with the beauty of a destroyed church or the usefulness of a particular bridge, or knows someone who's lost a beloved. In contrast, the grounds of that China earthquake's badness- the value of those temples, or those particular people, or life in third century Shu Hanare much less present in her life. So it's fitting for her to be unequally affected by these tragedies. In a similar manner, presumably, climbing feats matter because courage and perseverance and excellence do. So if Zara had had no contact whatsoever with the difficulties alpinism involves, the Annapurna ascent's admirability wouldn't be very present in her current life-facts. But since she knows this first-hand, these grounds are quite present for her-and more than the grounds of the admirability of that breath-hold dive. That's the rough picture.

This picture seems to give the right explanation in these cases. It also seems to explain why certain facts don't contribute to significance. Someone's height or hairnumber generally doesn't ground or make up the badness of their death. So your sharing such facts with them isn't a reason for you to care. The picture also seems able to capture our normative discretion in caring just right. To some extent you can determine which facts are present in your life. For instance, you're often free to decide what to attend to. So Zara may one day have decided to read a book about climbing, say. This will have made values in climbing more present for her. And the more that they were, and the more she's accordingly cared, the more present these values will have become. Thus she could fittingly start caring more about climbing than diving over time. Furthermore, the reasons of significance are arguably to some extent incommensurable-as the reasons given by most value-facts are-and don't determine a unique degree of caring that's fitting. So even given a fixed history of involvement with value-facts, Zara may always fittingly start to care somewhat less

\footnotetext{
${ }^{8}$ I speak of the facts that 'ground or constitute' a value-fact because some value-facts are arguably fundamental, but can still be more or less significant for you. In what follows, however, I'll focus on (what I take to be) non-fundamental value-facts and their grounds.
} 
about Colombia and somewhat more about China, say. ${ }^{9}$ Yet this discretion has limits. You can't fully determine the presence of facts in your life. If Zara sees someone dying, the grounds of the badness of their death are present for her: she's confronted with their suffering, or their desire to live, whether she wants it or notand decidedly more so than with the facts about some death in twelfth century Norway. Besides this extensional adequacy, I take it, the picture also seems based on a plausible core idea. Obviously, this idea is still rough. ${ }^{10}$ But I take it for present purposes this will suffice. So rather than elaborating on this general account, let's see how it applies to the reactive emotions.

Suppose an agent is culpable for wronging a victim. If I'm right, their culpability will be significant for you to the extent you're bound up with what constitutes or grounds it. So what will that be? Plausibly, at a very general level, their culpability will be grounded in the fact that their quality of will violated a demand of which the victim is a source and they are the objects. The victim's being a source of such demands will be grounded in (or perhaps just be) the fact that they're valuable, or have a form of dignity, or that it's valuable to them to live the life they choose, fare well, and be embedded as a member in equal standing in a moral community. If the victims weren't valuable in such manners, they wouldn't ground any moral demands. And at least on a Strawsonian conception, the agent's being an object of such demands will be grounded in (or perhaps just be) the fact that they're involved in standard 'inter-personal human relationships' (2008, p. 9) structured by answerability relations. If the agents weren't involved in such relations, they wouldn't be subject to such demands. The more concrete grounds of someone's culpability will depend on the correct moral theory, and presumably on the demand that they flouted, or on how they did. But take the demand against attitudes of aggression — or the fact that I (among others) am a source and you (among others) are an object of it. Presumably, that's (at least in part) because if you're aggressive you're disposed to act aggressively towards me, because in doing so you'll expectably injure me, and because such an injury in turn would be bad for me. If aggression wouldn't dispose you to actions, or if these actions couldn't harm me, you wouldn't wrong me in manifesting aggressive attitudes towards me.

Now, the extent to which we're bound up with these grounds yields a plausible explanation of the agent-relativity of the reactive attitudes, as illustrated by Dahir, Emma and Finn. Consider Dahir's aggression. The fact that Dahir's attitudes disposed him to likely effect something bad for his victim is little present in Zara's life. She isn't involved with Dahir's dispositions, the injuries they might cause, or their badness for his victims. All of this is located in fifth century Mali. So she may fittingly care rather little about the culpability of Dahir. That's different with her

\footnotetext{
9 For classic defenses of the pervasiveness of incommensurability, see e.g. Raz (1986, Chap. 13) or Broome (1997). For an analysis of incommensurability in terms of permissible ranges of attitudes, see e.g. Rabinowicz (2012, esp. 139 n.3), and relatedly Raz (1997).

${ }^{10}$ For instance, perhaps we can't assess the presence of some fact $p$ in the facts of your life by just counting arithmetically what proportion of your life-facts involve $p$. Perhaps 'presence' is a normatively somewhat richer notion. Perhaps it's multiply realizable in a countable number of key ways, and it would be possible to detail them.
} 
friend Emma. The fact that Emma's attitudes disposed her to expectably harm her victim is present in Zara's life-facts. She may not know the particular victim that Emma's just hit. So it's not so much the present harm that binds her up with her friend's fault. But Emma's attitude to her victim must express an attitude of hers towards people more generally. And insofar as Zara is involved with Emma, or with other people with whom Emma interacts, these attitudes of Emma's play a role in her life. Thus a relationship to the wrongdoer makes their culpability significant for us. It would be unfitting for Zara to care little. And something similar is true with stranger Finn who hit Zara's husband. The fact that Finn's attitudes disposed him to likely effect something bad for his victim is present in Zara's life. She might not have been or planned to be involved with Finn, or with other people with whom Finn interacts. So it's not so much Finn's attitudes towards people in general that bind her up with his fault. But Finn harmed her husband. And insofar as Zara's involved with the badness of this harm, Finn's dispositions play a role in her life. A relationship to the victim makes a wrongdoer's culpability significant for us. Again, it would be unfitting for Zara to care little.

\section{Significance and moral luck}

So much for the general picture. We're ultimately interested in moral luck. So let's now apply this account to our cases. The significance of Alice's, Belen's and Cleo's culpability for Zara depends on how much she's bound up with what constitutes or grounds it. So what is that? At a general level, the ground of their culpability is again that their attitudes violated a demand of which Yael is a source and they are the objects. In their case, I've assumed, it's the demand against being reckless. But plausibly, the grounds of this demand are very similar to those concerning aggression. Plausibly, Yael is a source and our agents objects of the demand against recklessness (at least in part) because if our agents are reckless they're disposed to act recklessly vis-à-vis Yael, because in doing so they'll expectably injure-or kill-her, and because this in turn would be bad for her. Reckless attitudes matter because reckless actions do. And reckless actions matter because deaths and injuries do.

Now Zara is bound up very unequally with these grounds, vis-à-vis our three agents. Take Alice. The grounds of Alice's culpability are little present in Zara's life-facts. Again, reckless dispositions matter because reckless actions do. But Alice never even acts on her dispositions. Indeed, the possible world in which she does is extremely remote. So Zara is little involved with the reasons for why Alice's dispositions would matter in the first place. For her, and as far as what ultimately matters is concerned, it's effectively as if Alice didn't have these dispositions at all. Alice's case is a bit like Dahir's. Quite like Dahir doesn't threaten anyone that Zara's bound up with, so neither does Alice. With Dahir that's due to his spatiotemporal distance, with Alice it's due to the modal remoteness. But the effect is the same. Zara may fittingly care rather little. That's different with Belen. Insofar as reckless dispositions matter because reckless actions do, the grounds of Belen's culpability are quite present for Zara. It isn't just far away or in some remote world 
that Belen would actually threaten someone. She does, here and now, and with Zara's very own child. So the reasons for why Belen's dispositions are objectionable is quite real among Zara's life-facts. She is involved with what renders Belen culpable. We can compare her case to Emma's. Zara wasn't so much bound up with the actual harm Emma caused, as she didn't know Emma's victim. But she was bound up with Emma's attitudes, because they potentially threatened people she's involved with. Similarly, Zara isn't bound up with the harm that Belen causes, as Belen doesn't cause any harm. But she's bound up with Belen's attitudes, since they threaten people Zara is close to. Belen's culpability concerns her more than Alice's. She can't fittingly care equally little. However, reckless actions ultimately matter because deaths and injuries do. And it's only in a possible world that Belen actually touches Yael. To that extent, the reason for why Belen's actions matter aren't actually present for Zara. For her, and as far as what matters is concerned, it's still as if Belen hadn't acted at all. And that's different with Cleo. It isn't that Cleo harmed someone distant, or only harms Yael in some remote world. She actually killed her. So Zara is involved real hard with what renders Cleo's actions objectionable to begin with. We can compare her case to Finn's. Zara was bound up with Finn's culpability because she cared about the actual harm that he caused. And she's bound up with Cleo's culpability for the same reason. Cleo's culpability concerns her still more than Belen's. She ought to care even more.

In short, the fact that if someone has a certain disposition they'll act in certain ways under certain conditions is more present in our lives if these conditions actually hold. And the fact that if someone acts in certain ways they'll expectably harm someone is more present if they actually do. We're unequally involved with people's culpability, depending on the modal distance of their actually affecting us - quite like we're generally unequally involved with it depending on their spatiotemporal distance.

So that's our initial cases. Now I think this argument generalizes importantly beyond them. First of all, it isn't restricted to recklessness, but seems plausible for any objectionable attitude that can bear moral luck. The crucial premise about recklessness was that its objectionability is partly grounded in the badness of its possible effects. And that's arguably true for any attitude subject to luck-such as attitudes of paternalism, injustice or disloyalty, say. Paternalist attitudes are objectionable at least in part because they cause interferences with people's lives, and because such interferences are problematic. If they couldn't cause actual encroachments, or if the latter in themselves weren't worrying at all, then why should paternalist attitudes be? And the same goes for attitudes of injustice or disloyalty or whatever. Such attitudes are problematic, at least in part, because there's some prior value - a just or equal society, or relationships of mutual trustand because in some form or other these attitudes expectably effect infringements of it. So for any objectionable attitudes, an equivalent of the above argument could be made. ${ }^{11}$ Moreover, the argument isn't restricted to Zara, but applies to third parties

${ }^{11}$ One may wonder whether I'm presupposing a narrowly consequentialist framework. But I'm not. My argument only presupposes that the objectionability of attitudes is partly grounded in properties of what they expectably effect. Perhaps it makes a difference, from my perspective, whether I or someone else 
too. Suppose Xenia lives at Bogotá's opposite end, had never heard of Yael, and hears about our agents. It's fitting for her to care much less than Zara about their culpability: she's less bound up with the wellbeing of anyone they threaten or kill. But the (potential) death of a stranger mustn't leave us totally cold, of course. After all, the badness of Yael's death is also grounded in very general facts about human life, or life in twenty-first century Colombia, and these facts will be present in Xenia's life too. Even she should care (somewhat) about Yael's death, and should care about the attitudes of our agents because she cares about Yael. And to that extent the above rationale will apply to her. She's (somewhat) unequally bound up with the reasons for why our agent's attitudes are objectionable to begin with. So other things equal, it's fitting for her to respond with (somewhat) unequal indignation to them. ${ }^{12}$

\section{Our desiderata, and a remaining worry}

If all of this is true, unequal responses to our cases don't simply reflect a bias. Nor is it simply in virtue of consequentialist reasons that such responses are somehow warranted (see e.g. Jensen 1984). Instead, it's fitting for Zara to respond with unequal indignation to Alice, Belen and Cleo, as the luck-advocates maintain. Indeed, we have an account that can meet the desiderata from Sect. 2. So let me now elaborate on these challenges, before I address a final and more fundamental worry. Recall what we aimed to provide. First of all, we needed an independent positive argument for the claim that our agents don't just warrant unequal sadness or concern, in addition to equal blame, but that blame itself is sensitive to significance such that their unequal luck warrants unequal blame. We can now give such an argument. This claim simply follows from a very general and independently plausible picture of emotions. Very many kinds of value-facts can be (more/less) significant for you, and if they are, it's fitting for you to be (more/less) affected by the emotions they intrinsically warrant. A value fact will be significant for you to the extent that what grounds or constitutes it is present in the facts of your life. And the grounds of Cleo's culpability are more present in Zara's life than those of Belen's, and those of Belen's more present than those of Alice's. So it isn't just other, extra

\footnotetext{
Footnote 11 continued

ends up harming (as e.g. Williams 1973, p. 93ff. suggested). So perhaps the objectionability of my recklessness is also partly grounded in it's expectably making me injure someone. And thus perhaps I mustn't drive recklessly even if I could thereby prevent two other people from doing so. This wouldn't affect the above rationale. So it's perfectly compatible with deontological or standard virtue ethical frameworks. The only theory I can think of for which it may not go through is what Slote (2001) called 'agent-based virtue ethics'. On this theory, facts about attitudes are fundamental. So the immorality of recklessness is brute, and not grounded in its being bad for others if we harm them, or problematic if we curtail their freedom, or some such (2001, p. 7). But this simply seems to get the order of explanation plain wrong.

12 I say 'other things equal' because there are other factors that determine the significance of faults, such as those discussed in Sect. 4. If Xenia doesn't know Cleo but is a longstanding colleague of Belen's, Belen's fault might ultimately be more significant for her than Cleo's.
} 
emotions, that Belen and Cleo invite. It's fitting for Zara to react with more indignation to Cleo than to Belen, and to Belen than to Alice. To resist this, a luckskeptic must either show that there's something wrong about our general account of emotions. Or they must hold that there's something peculiar about the reactive attitudes, setting them apart from other responses.

This indicates that we can also meet the second desideratum. The worry was that Scanlon's idea only applies to undemanding forms of 'holding people responsible'-like Scanlon-blame-but not to more demanding practices of doing so. I've now argued that the idea applies at least to resentment or indignation, which seemed our most demanding responsibility-practice. In some sense Strawson's right that these attitudes are 'essentially reactions to the quality of others' wills' (2008, p. 15; my emphasis). They aren't directly, so to speak, responses to actions. But as with other emotions, they're also responses to our involvement with the grounds of their value-facts. And culpability-facts are often grounded in facts about actions-in the fact that certain qualities of will dispose you to do certain things, or that these actions expectably harm. So in this indirect sense, the reactive attitudes are also responses to actions, and to factors subject to luck.

The third desideratum was to show that equal blame would manifest an insensitivity to the moral considerations at issue, and amount to a morally problematic response. And that's what our account now suggests. Note what mistake Zara'd make in responding equally to our agents. Consider first Dahir, Emma and Finn. Suppose Zara doesn't care at all about the wellbeing of anyone in fifth century Mali, but cares very much about that of her husband and the people with whom Emma interacts. And suppose she nonetheless cared precisely as much or little about Emma and Finn's culpability as about Dahir's. This would be peculiar indeed. Again, their aggressiveness matters because their (potential) victims' welfare does. So if Zara cares very unequally about the latter, but gets equally worked up about the former, she'd have to care about their faults for wrong reasons. She'd have to misconstrue why their aggressiveness matters morally in the first place. More specifically, she'd have to turn their culpability into a fetish: treat it as an independent value-fact, with brute or fundamental importance, and disregard its groundedness in the prior value of people's wellbeing. To care equally about these faults would manifest a problematic mere-matter-of-principle concern. Now if Zara cared equally about the culpability of Alice, Belen and Cleo she'd make the same sort of mistake. Their culpability ultimately matters because Yael's welfare does. And our agents affect that very unequally. So to care equally about their culpability, regardless of what happened or could have happened or with what modal remoteness it may have, is a way of radically misconstruing why it has import to begin with. Again, it's to turn their faults into a fetish or mere-matter-of-principle concern: to treat their importance as brute, or being worth caring about for no prior reason. It's an insensitivity to the order of moral facts, or to the moral considerations at issue.

In sum, we've developed the initial idea in a manner that meets our demands: we now have an independent argument for why Zara's equal indignation at our agents would be a morally problematic response. The emerging key thought is that what determines the significance of someone's fault for us isn't some prudential or non- 
moral factor. It's what gives their attitudes moral import in the first place. So being insensitive to luck must mean fetishizing the wrongfulness of people's attitudes, or detaching them from their ultimate wrong-makers. Now I've only considered the standard reactive attitudes as a blame-response. So one might take all of this to show that these attitudes aren't our most demanding practice of responsibility after all. Or at any rate, one might hold we could contrive a pure practice of holding people responsible — a 'shreactive attitude', say—that's sensitive to people's culpability only, and not to its significance for us. And for all I see we could. But I think the above rationale is probative. Suppose the shreactive attitude isn't just a culpabilityjudgment, but involves a form of sanctioning, responding to, or practical-attitudinal caring about faults. If culpability matters because victims do, then this attitude will look fetishistic in precisely the just-mentioned way. It will express a morally dubious mere-matter-of-principle concern. So I take it the above rationale doesn't just show that the reactive attitudes are sensitive to luck. It shows that any morally sensible practice must be.

There's a more fundamental worry that all of this raises, and that we finally need to confront. One way of putting my conclusion is that although our agents are equally responsible for the same moral faults, we shouldn't hold them equally responsible for them: there's a distinction between culpability-facts and our culpability-practices, and moral luck affects only the latter. But some skeptics might say they never wanted to make any practical claim about how it's fitting to respond to our agents. They only claimed that our agents are equally culpable, or deserve equal blame in some much more basic sense, independent of fitting-attitude facts. Our responses are a different kettle of fish, and may well be sensitive to all sorts of factors. These skeptics made a claim about metaphysics (see e.g. Zimmerman 2002, p. 556; Enoch and Marmor 2007, p. 412). So isn't all of this still a red herring, or indeed a concession of the core skeptical claim?

I have nothing substantive to object to this stance. If some skeptic merely claims that our agents are (in my terminology) equally culpable, then I fully agree. In this sense there's no moral luck. I don't think that's a problem for my argument. To the contrary, I think it's a nice feature of it. The argument starts from a non-trivial skeptical premise. And if some skeptics were just concerned with culpability-facts, nothing must stop them from accepting my conclusion. So my argument seems more widely acceptable than other vindications of luck, on which culpability is intrinsically sensitive to it (see e.g. Hartman 2017). Still, I'd urge, if they do accept my conclusion, the skeptics have granted something very substantial. The skeptical tenet is as it were a purely academic or theoretical truth, relevant only within the detachedly macroscopic horizon of all possible worlds, or the narrowly microscopic focus on the intrinsic properties of our agents. It's a truth that's always overridden in the modal and spatio-temporal situatedness of our lives. Indeed, it's a truth that it would be fetishistic to put unfilteredly into practice. With respect to what's practically morally relevant, the luck-advocate position is right. And I take it that we (or most of us) are concerned about culpability, at bottom, because we're concerned about practical moral questions. We're interested in free will because we're interested in how we morally ought to feel about ourselves, or how we ought 
to treat people, or respond to them. And we're concerned about luck for the same reasons. And insofar as that's so, my conclusion is pertinent and substantial indeed.

The comparative superficiality of the remaining truth in skepticism may be illustrated by the notion of fairness. One might continue to feel that it must be unfair to blame our agents unequally. Specifically, one might suggest fairness demands that everyone be treated as according to their culpability they deserve-so that given their equal culpability our agents be treated the same. And again, I wouldn't want to object to this. Perhaps that is what fairness requires. But if so it just shows that such fairness isn't decisive in practice. Consider Dahir and Finn one last time. We've assumed they were equally culpable, but that Zara had nothing to do with Dahir's fault, but was closely bound up with Finn's. Indeed, let's assume that Dahir and his victim were loners, and that Finn and his victim were well-known, so that very many people are in a position like Zara's. And suppose that their (un)popularity was beyond their control, even beyond what they could have known at the time of their actions. Then perhaps there's something unfair if all these people respond so unequally to Dahir and Finn: no one treats them, and the world won't repay them, as according to their culpability they are due. But this hardly means that our twenty-first century Colombians ought to blame that third century Malian wrongdoer as much as the perpetrator in their midst. The only ways to insist on fairness here would be to demand either fetishism or agent-neutrality-our caring equally about people's faults even if we care very unequally about their grounds, or our caring equally about the wellbeing of everyone ever on the planet. But neither demand seems plausible. Much more plausibly, whatever fairness-reasons there are, they're overridden by the reasons of significance. In blaming we should, quite simply, not primarily be concerned with making the world a fair place. And the same is true in cases of luck. Again, perhaps there's something unfair if Zara and many others blame Cleo much more than Alice. But this doesn't mean they ought not. The only ways to insist on fairness here would be to demand either fetishism, or a sort of modal neutrality-our caring equally about a death that could have happened as about one that actually did. But that doesn't seem plausible either. Again, Zara's fairness-reasons are overridden by her reasons of significance. Or in sum, while my argument starts from a skeptical premise and should thus be relatively widely acceptable, the skeptical remnants in the conclusion are comparatively inconsequential. It provides a vindication of moral luck in a more substantial sense than it constitutes a denial of it. ${ }^{13}$

\footnotetext{
${ }^{13}$ My argument also shows that it's possible to construct a three-place notion of 'blameworthiness', on which how blameworthy you are for an action, for me, is a function of your quality of will and of the significance that it has for me. On this notion, how much you're worthy of my blame partly depends on how much your fault is worthy of my caring. I think that's a legitimate philosophical notion. But since our common-sense notion doesn't seem agent-relative, I prefer my way of conceptualizing things.
} 


\section{Conclusion}

Let me conclude. I've argued that our agents' faults are unequally significant for Zara, and that this grounds a vindication of moral luck. There are a number of interesting lines of research that this argument invites. For one thing, the general account of significance could be rendered more precise. This would be a contribution to the theory of emotions in general, provide a more elaborate version of the present argument, and might have other interesting implications about the reactive attitudes-such as for when it's appropriate to overcome your resentment and forgive someone for a fault. ${ }^{14}$ Furthermore, the account could be applied to other practices of responsibility, beyond the emotions I've considered.

One particularly interesting application of the latter kind, related to moral luck, concerns punishment. Notoriously, in most (or all?) jurisdictions, punishment is sensitive to luck. So there's a question about whether this can be justified (see e.g. Enoch 2010 for a survey). The present account might ground parts of an explanation. To begin with, it might explain why our agents have unequal claims against us not to be punished. Perhaps people's claims not to be punished correspond negatively to the degree with which, in light of their culpability, we may appropriately qualify our goodwill towards them. Perhaps as Strawson (2008, p. 23) suggested, the appropriate qualification of goodwill corresponds to the strength of the appropriate negative reactive attitude to them. And perhaps that's true even in light of the significance that the latter are sensitive to. If so, perhaps Cleo doesn't have a claim that we normalize our attitude and let her out of prison, say, after just one week. But Belen might have such a claim, since in her case nothing happened. And the same would be even more true for Alice (who anyway, and for other reasons too, shouldn't be punished at all). The account might also ground a more positive reason to punish Cleo more than Belen. Perhaps punishment has an expressive function. And perhaps it shouldn't just express that certain attitudes or actions are objectionable, but also that we care about them because we care about their victims. Perhaps in punishing our agents equally, we'd express that we care equally about their faults, and this message would be disrespectful towards Zara or Yael. Incidentally, the account might also explain other aspects of punishment. Presumably, the 'we' that issues punishment is a particular present moral community. And long-past perpetrations seem generally less significant in the present. So this might partly explain why perpetrations can expire by limitation.

But these are matters for another paper. My main concern here was with blame. And I hope I've vindicated that blame is sensitive to luck. For we shouldn't make a fetish of faults.

Acknowledgements I thank Barbara Bleisch, Susanne Boshammer, Berit Braun, Francesca Bunkenborg, Alexander Dietz, Robert Hartman, Samuel Hughes, Markus Kneer, Felix Koch, Benjamin Lange, Adam Lovett, Leonhard Menges, Lukas Naegeli, Claire Plassard, Peter Schaber, Thomas Schmidt, Philipp Schwind, Philipp Reichling, Christian Tarsney, Felix Timmermann, R. Jay Wallace and Eva WeberGuskar for very helpful comments on this material.

\footnotetext{
${ }^{14}$ I explore this in 'Forgiveness and the Significance of Wrongs' (unpublished manuscript).
} 


\section{References}

Broome, J. (1997). Is incommensurability vagueness? In R. Chang (Ed.), Incommensurability, incomparability and practical reason. Cambridge, MA: Harvard University Press.

Browne, B. (1992). A solution to the problem of moral luck. The Philosophical Quarterly, 42(168), $343-356$.

Cholbi, M. (2014). Luck, blame, and desert. Philosophical Studies, 169(2), 313-332.

D'Arms, J., \& Jacobson, D. (2000). The moralistic fallacy: On the 'appropriateness' of emotions. Philosophy and Phenomenological Research, 61(1), 65-90.

Domsky, D. (2004). There is no door: Finally solving the problem of moral luck. The Journal of Philosophy, 101(9), 445-464.

Enoch, D. (2010). Moral luck and the law. Philosophy Compass, 5(1), 42-54.

Enoch, D., \& Marmor, A. (2007). The case against moral luck. Law and Philosophy, 26(4), 313-332.

Frankfurt, H. (2004). The reasons of love. Princeton, NJ: Princeton University Press.

Hanna, N. (2014). Moral luck defended. Noûs, 48(4), 683-698.

Harman, G. (1999). Moral philosophy meets social psychology: Virtue ethics and the fundamental attribution error. Proceedings of the Aristotelian Society, 99, 315-331.

Hartman, R. (2017). In defense of moral luck: Why luck often affects praiseworthiness and blameworthiness. Abingdon: Routledge.

Helm, B. W. (2009). Emotional reason: Deliberation, motivation, and the nature of value. Cambridge, MA: Cambridge University Press.

Jensen, H. (1984). Morality and luck. Philosophy, 59(229), 323-330.

Kolodny, N. (2010). Which relationships justify partiality? The case of parents and children. Philosophy and Public Affairs, 38(1), 37-75.

Kumar, V. (2018). Empirical vindication of moral luck. Noûs. https://doi.org/10.1111/nous.12250:1-21.

Levy, N. (2011). Hard luck: How luck undermines free will and moral responsibility. Oxford: Oxford University Press.

Lovett, A., \& Riedener, S. (2019). On keeping things in proportion. Journal of Ethics and Social Philosophy, 16(3), 229-258

Moore, M. S. (2009). Causation and responsibility: An essay in law, morals, and metaphysics. New York: Oxford University Press.

Nagel, T. (1979). Moral luck. In Mortal questions. Cambridge, MA: Cambridge University Press.

Nussbaum, M. C. (2001). Upheavals of thought: The intelligence of emotions. Cambridge, MA: Cambridge University Press.

Peels, R. (2015). A modal solution to the problem of moral luck. American Philosophical Quarterly, 52(1), 73-87.

Pereboom, D. (2001). Living without free will. Cambridge, MA: Cambridge University Press.

Pereboom, D. (2014). Free will, agency, and meaning in life. Oxford: Oxford University Press.

Rabinowicz, W. (2012). Value relations revisited. Economics and Philosophy, 28(2), 133-164.

Raz, J. (1986). The morality of freedom. Oxford: Clarendon.

Raz, J. (1997). Incommensurability and agency. In R. Chang (Ed.), Incommensurability, incomparability and practical reason. Cambridge, MA: Harvard University Press.

Rescher, N. (1990). Luck. Proceedings and Addresses of the American Philosophical Association, 64(3), 5-19.

Riedener, S. (2019). The standing To blame, or why moral disapproval is what it is. Dialectica, 73(1-2), $183-210$

Scanlon, T. M. (2008). Moral dimensions: Permissibility, meaning, blame. Cambridge, MA: Harvard University Press.

Sharadin, N. (2016). Reasons wrong and right. Pacific Philosophical Quarterly, 97(3), 371-399.

Slote, M. (2001). Morals from motives. New York: Oxford University Press.

Smith, A. (2002). In K. Haakonssen (Ed.), The theory of moral sentiments. Cambridge, MA: Cambridge University Press.

Stout, N. (2017). Salience, imagination, and moral luck. Philosophical Papers, 46(2), 297-313.

Strawson, P. F. (2008). Freedom and resentment. In Freedom and resentment and other essays. Abingdon: Routledge.

Thomson, J. J. (1989). Morality and bad luck. Metaphilosophy, 20(3-4), 203-221.

Walker, M. U. (1991). Moral luck and the virtues of impure agency. Metaphilosophy, 22(1/2), 14-27. 
Williams, B. (1973). A critique of utilitarianism. In Utilitarianism: For and against. Cambridge, MA: Cambridge University Press.

Williams, B. (1981a). Internal and external reasons. In Moral luck. Cambridge, MA: Cambridge University Press.

Williams, B. (1981b). Moral luck. In Moral luck. Cambridge, MA: Cambridge University Press.

Williams, B. (1995). Moral luck: A postscript. In Making sense of humanity. Cambridge, MA: Cambridge University Press.

Wolf, S. (2013). The moral of moral luck. Philosophic Exchange, 31(1), 5-19.

Zimmerman, M. (1987). Luck and moral responsibility. Ethics, 97(2), 374-386.

Zimmerman, M. (2002). Taking luck seriously. The Journal of Philosophy, 99(11), 553-576.

Publisher's Note Springer Nature remains neutral with regard to jurisdictional claims in published maps and institutional affiliations. 